\title{
The Brazilian Journal of Geology is part of the SciELO
}

In this short editorial it is with great pleasure I announce that on September $1^{\text {st }}$ I received the long expected information that, by decision of the Advisory Committee of SciELO Brazil, in their meeting held on August 29 ${ }^{\text {th }}$,2014, the Brazilian Journal of Geology (BJG) was considered fit to join the Brazilian SciELO Collection. With the help of our competent and diversified editorial board, the editorial actions conducted with professionalism, and with the continuous flow of good quality scientific articles produced by our national community, we were able to fulfill one of our most important goals.

SciELO - Science Electronic Library On-Line — is a virtual library of Brazilian scientific journals in electronic format. Its mission is to organize and to publish complete texts of Internet journals, as well as to produce and to publish indicators of their use and impact. With the use of Internet, SciELo has developed a methodology for rapid electronic publishing, with open access and universal coverage. This methodology includes the preparation and assessment of electronic scientific publications, which has technically enabled the transition process between traditional printed publishing to the electronic format.

The first phase of SciELO was developed in 1997-1998, as a result of the partnership between FAPESP, the Centro Latino-Americano e do Caribe de Informação em Ciências da Saúde (Bireme) and editors of scientific journals, whose main goal was to increase the visibility of national scientific production. The Revista Brasileira de Geociências (RBG) was part of the reduced initial number of participant Brazilian journals, but, unfortunately, it had to be prematurely excluded from the program by lack of punctuality. Since the mid-2011, the RBG had recovered its punctuality and, at that time, the board of Brazilian Geological Society (SBG) decided it would be important to promote an editorial restructuring of the journal in order to obtain greater visibility worldwide, seeking for its indexing in the main bases of international journals, such as SciELO and, later on, the ISI. The Editorial Board created by SBG in the beginning of 2012 decided the pursuit for its reinstatement in SciELO collection as one of the main goals to be achieved by the journal.

The evaluation process by the Advisory Committee of SciELO, based on the international criteria adopted by the more important databases, is strict and complete. The journals are assessed obviously for their scientific quality, but also for other criteria, such as:

- Publishing, predominantly, original contributions;

- Practicing and reviewing the approval of the contributions by peers;

- Having an editorial committee, whose composition is public;

Keeping regular periodicity and punctuality on the publication;

- Time of existence of the journal;

- Presenting abstracts, titles and keywords in English, whenever this is not the language of the article;

- Specifying the standard norm adopted by the journal and effectively embracing it.

The criteria above are verified by SciELO through the analysis of some consecutive issues of the journal, and various interactions with the editors are made, with objective and direct comments and suggestions. In the case of BJG, the main comments concerned the strict maintenance of punctuality. Also, the need to increase the use of English was suggested. As for this last point, as it has already been indicated in several of our last editorials, the Board of BJG is prioritizing articles in English. Furthermore, it seems that there has been a decrease in the Brazilian geoscientific community posture on encouraging the publication of articles in Portuguese, on the grounds that it would be important to protect our mother language. I understand that the decrease in the resistance of using English is auspicious. It is a fact that this is the language of science. Publishing in English obviously allows greater visibility of the publications indexed in international databases. For me, the best evidence of that is that countries which intend to be scientifically visible 
and competitive, such as France, German and Italy, not to mention China and Russia, have already changed the names of their main journals into English, as indeed is the case of our BJG, and have already been publishing their scientific material in the language of science.

The evaluation process of BJG by the Advisory Committee of SciELO, which analyzed and monitored the development, the contents and the punctuality of the journal, began in early 2013, and took less than two years to be concluded. The advantage of belonging to SciELO — sharing with the best Brazilian scientific publications a common and advanced methodology on the creation of on-line libraries of scientific journals — will allow the Brazilian Journal of Geology to have a radical increase in its accessibility and visibility in the scientific literature and will surely contribute for its greater impact as well.

Umberto Giuseppe Cordani Editor in chief 